\title{
HYBRID WARFARE AND THE CHALLENGE IT POSES TO PSYCHOLOGICAL RESILIENCE TRAINING IN THE BULGARIAN MILITARY
}

\author{
Krassen DASKALOV
}

\begin{abstract}
The article provides an overview of hybrid warfare and psychological resilience, and the related challenges faced by individuals, communities and societal security in regard to the psychological effects of hybrid threats. Since the concept of psychological resilience is new and almost unknown in Bulgaria, and even less so in the Bulgarian military, the article introduces the reader to the concept of psychological resilience. It then suggests a model of developing resilience training in the Bulgarian armed forces.
\end{abstract}

Keywords: resilience, hybrid warfare, security, military, training programme.

\section{Introduction: The Concept of Resilience}

The issue of hybrid warfare has entered the public debate, even though the phenomenon itself is not new. It combines military, economic, political and other non-physical activities to achieve political objectives. Frank Hoffman's paper on hybrid wars ${ }^{1}$ triggered huge interest among military and policy leaders and in military organizations. Hybrid threats incorporate a full range of different modes of warfare, including conventional capabilities, irregular tactics and formations, terrorist acts including indiscriminate violence and coercion, and criminal disorder. Historically, many wars have had both regular and irregular components. However, in most of the cases, those components occurred at different stages, theatres or formations. In hybrid wars, those forces emerge in the same force at the same time and in the same battle space.

According to Hoffman's study, the emergence of this new type of warfare does not mean that the traditional warfare has disappeared. On the contrary, besides conventional warfare, hybrid war will complicate the defence planning in the future. Due to the influence of hybrid war, one has to consider many other creative approaches to developing innovative thinking. This could be very challenging to the military training system which is recognized as promoting more obedience, conformity, and compliance instead of initiative, creativity, and critical thinking. 
The skills required to cope with uncertainty provoked by hybrid warfare necessitate mental agility and tolerance to ambiguity to recognize and quickly adapt to the unknown and unexpected. Also, besides decision-making skills and tactical abilities of military leaders, military policy itself can comprise specific actions in order to design and develop the military organizations as a proper training environment for preparing the future hybrid warriors in diverse experiences, equipped with all required traditional and new skills, including or together with resilience. This will require not just modifying our mindset but also, in order to achieve all requirements for confronting this new mode of war, a rapid adaptation at both individual and institutional level.

As early as 2013, Pospisil argued that resilience would become an enticing concept for security policy. Linking resilience with risk, he deemed possible a fundamental reconfiguration of security policy through the resilience paradigm. ${ }^{2}$

The origins of the term resilience are still unclear. The term is attractive as it suggests the ability of someone to cope in the face of adversity - to recover and return to normality after confronting an abnormal, alarming, and often unexpected threat. Resilience embraces the concepts of awareness, detection, communication, reaction (and, if possible, avoidance) and recovery. These are essential features of life and are founded in our basic instinct of survival. Resilience also suggests an ability and willingness to adapt over time to a changing and a potentially threatening environment.

The term resilience has been used for over three decades in assessing how well individuals cope in traumatic situations. Early works focused on the resilience of children, but it has broadened to encompass the ability of adults to manage abnormal situations, particularly their involvement in war, disasters and even 'routine' abnormal events such as major traffic accidents. ${ }^{3,4}$

There are two important areas of agreement in the literature regarding the resilience of individuals. The first is the issue of adaptability. Individuals who are able and willing to adapt are more likely to reduce their risk of being exposed to disruptive events, or at least to reduce the impact of such exposure; resilient individuals are likely to be able and willing to adapt. The second is the issue of transient dysfunction. Resilience does not preclude dysfunction or distress; indeed, the absence of dysfunction or distress in an individual suggests resistance rather than resilience. It is now commonly accepted that some dysfunction or distress is a normal reaction to an abnormal event. However, dysfunction or distress is temporary, followed by a return to normal or better functioning.

Resilience aims at reducing the impact of events and recovering afterwards, but not necessarily preventing them. ${ }^{5}$ Hence, the rise of resilience was accompanied by a radical shift of security logic. Brassett, Croft and Vaughan-Williams refer to Mark Duffield who argued that the emergency planning of the late $20^{\text {th }}$ century was based 
on the prediction of events, isolation, and relocation of threats and the protection of the society, using military means. In stark contrast, nowadays resilience requires the society to learn new skills and be prepared so that it is able to "exploit the emergent opportunities that disorder inevitably creates." 6

McAslan identifies seven characteristics of resilience. First, resilience always refers to threats or dramatic events, which have a potentially overthrowing impact on a system. Secondly, resilient systems strive for a positive outcome, be it either the restoration of the status quo or change and improvement. These two outcomes are commonly known as 'bounce back' or adaptation. Thirdly, resilient systems need to be prepared either by standards, operational procedures, human or social capital, etc. Meanwhile, preparedness is but one important aspect of resilient systems, as they need to be willing and able to adapt to a constantly changing environment. Adaptability hence is the fourth characteristic of resilience. Fifth comes the willingness to learn and gain experience. Coordination and interdependency form the sixth characteristic, meaning resilient systems and nations "tend to be those which are well coordinated and share common values and beliefs." The core belief, and seventh characteristic, of resilience is the desire to survive. These characteristics make the concept of resilience "a powerful and useful concept," McAslan concludes. ${ }^{5}$

Besides being a powerful concept, resilience is inherently neoliberal as society is in a constant state of emergency and threats are ubiquitous. Brassett, Croft and VaughanWilliams argue that uncertainty becomes the starting point for neoliberal governance. ${ }^{6}$ The incapacity of the nation state to provide security to every individual, community or business necessitates that these subjects manage their own risks. Joseph goes as far as to argue that the subjects are indeed encouraged to "take responsibility for their own social and economic well-being" rather than relying on the state. He goes on to focus on the risk and security aspects of a neoliberal way of governance encouraging "preparedness and awareness." ${ }^{.7}$ While resilience promotes a concept of active citizenship, it does not ultimately provide any guarantees. Dunn and Prior argue, that resilience "currently enjoys an international status as a panacea for modern security challenges, as it leaves room for a new kind of subjective perception of security, despite the unpredictable nature of contemporary hazards." $"$

\section{Hybrid Threats, Security and Resilience}

Berzins stresses that hybrid warfare encompasses information, moral, psychological and ideological measures targeted at the society as a whole and selected political and military personnel as well. ${ }^{9}$ Mölling argues that a hybrid security strategy could put the European Union in the position of countering "adversaries in the non-military arena to prevent an escalation toward military force." 10 As a consequence, the first line of defence must be the build-up of a resilient collective mindset, which is able to 
withstand disinformation without cutting off freedom of speech or using indoctrination. As Andersson states, "a society's ability to defend itself crucially depends on its population having a critical mind." 11

As seen, the terms security and resilience are often used together, in particular at the national level. Both share common roots and requirements: the need to assess threats and vulnerabilities; the need to develop plans and procedures; and the need to have access to accurate and timely information. There are also advantages in bringing together national security and resilience. First, the large investment which is being made in national security, such as upgrading communication systems, improving national risk assessments, and hardening a country's critical infrastructure, including utilities and transport, is making the country more resilient. Also, by bringing together resilience and national security, the government has more control over the instruments of resilience at the state level, and by doing so is better able to encourage a greater degree of standardization and interoperability between the first responders, such as the police, fire authorities, health bodies and the volunteer state emergency services.

There are, however, significant areas of difference and departure between national security and resilience. The threats to national security are usually inspired by the forces of other countries or terrorists who aim to destabilise the government and its people, and national security aims to block or defeat such threats. In contrast, resilience involves an ongoing process of assessing a broad range of risks and threats, preparing to face such threats, accepting that some threats will become disruptive events, reducing the impact of events when they occur, and recover afterwards.

Resilience also requires an understanding of the needs and expectations of society, and how these needs and expectations are developing over time. Countries have nurtured a strong and admirable tradition of their communities supporting one another in times of trouble. But such national resilience cannot be taken for granted and there are signs that society is becoming more brittle than in previous generations, which in turn increases the need for more investments and efforts by the governments and local authorities in providing technical security measures to compensate for the diminishing resilience of families, groups, and communities.

In 2015, the European Union started to work on a new security strategy in which resilience plays an important role, illustrated by the following key recommendation:

The ESS should prioritize the set of threats Europe faces in terms of the severity of the impacts and decide how to respond through the lens of societal resilience. Such an approach can be made to work for a wide range of threats and so can be highly cost-effective. Resilient societies that have built-in ways and 
means to absorb or spread shock will manage their responses far more effectively than ill-prepared, more fragile communities. ${ }^{12}$

\section{Resilience of Military Personnel}

Resilience is vital for military service members to survive under potential threats to their own lives and safety and to accomplish assigned missions, often for the sake of others' survival and welfare. The ability of service members to bounce back from operational stress may also determine how successfully they reintegrate with their families and communities, whether they can continue to effectively perform their military profession, or whether they develop potentially disabling mental disorders or other serious behavioural problems.

The genealogy of military resilience is deeply tied to shifts in the discipline of psychology. It should be noted at the outset that there are very strong ties between the military and the profession of psychology in the USA. These ties are historical. In the $20^{\text {th }}$ century, American psychology was professionalized and turned into an applied discipline largely through its engagements with the military. During World War I, psychologists developed intelligence tests and assessed soldier proficiencies so as to place draftees in specialty areas according to their abilities, positioning psychology as a discipline useful for the conduct of war as well as for personnel management, making the discipline more applied. During World War II, the role of psychologists expanded (in part because of the shortage of psychiatrists) to include treatment and morale enhancement, as well as refined aptitude tests. Out of the experience of World War II, clinical psychology gained authority as a profession.

It is through its utility in warfare and military science that psychology transformed from a fledgling discipline to an academic, clinical, and applied profession. ${ }^{13}$

Almost any mission with which a military unit may be tasked can expose service members to mortal danger, loss, and moral compromise with an intensity and relentlessness hard to imagine in most other settings. ${ }^{14-16}$ Returning from deployment exposes service members to an entirely different set of adaptation challenges, some of which may be just as overwhelming as those experienced during deployment. Examples include the stress of coming home to a broken family, a lost civilian job, or financial ruin. Both during and after deployment to an operational theatre, service members face the challenge of mourning losses, finding meaning in experiences that seem senseless, and making peace with enduring memories of death and destruction. Resilience challenges for military service members and the organizations that support them, therefore, arguably encompass at least three broad forms:

(1) Operational resilience, which may be defined as the ability to maintain occupational role functioning and psychological performance during opera- 
tional deployments despite stressor exposures, and perhaps despite internal distress and conflict; ${ }^{17}$

(2) Post-deployment resilience, which may be defined as the ability to reacquire and maintain effective role functioning in largely non-military settings after returning from deployment, and so again to be a productive member of a family and civilian society;

(3) Psychological resilience, which may be defined as the ability to adapt physically, mentally, and spiritually to operational stressor exposures, and sometimes the lasting changes they engender, without developing a significant mental disorder or behavioural problem.

The science of psychological resilience is increasingly seen as a tool to successfully man $21^{\text {st }}$ century wars. In much of the Western military thinking, resilience is now seen as an indispensable resource and necessary characteristic of modern warriors, and human beings more generally.

The psychological science of resilience is being developed with two aims: first, it aims to produce a fit fighting force in order to wage war more effectively; and second, it aims to reduce healthcare costs and entitlements by preventing mental health difficulties. The line of thinking here is that if disordered responses to adverse life events can be prevented, then soldiers will not require costly treatment.

Military organizations have long traditions of selecting, training, and sustaining service members to endure intense and persistent operational stress without losing their abilities to function on the battlefield, but resilience has only recently attracted sustained interest from the military. As military organizations develop programmes to promote a broader spectrum of desired stress outcomes, they are faced with a choice between expecting traditional resilience-building methods to meet untraditional objectives and creating entirely novel approaches to resilience.

Academic interest in the psychological, biological, social, and personality-trait differences associated with successful adaptation to combat and operational experiences has increased rapidly since the late 1990s. Underlying recent studies in this area has been the assumption that the incidence of various mental health and functional problems associated with combat and operational experiences might be reduced if modifiable risk and resilience factors could be identified and then targeted in military prevention programmes. Unfortunately, research and translational programmes to enhance resilience in members of the armed services have, so far, been limited by the lack of a unified or paradigmatic approach to conceptualizing the military and extramilitary processes and functions that may lead to resilient outcomes, and even by the lack of a consensus definition of resilience. Uniform methods of measuring resilience processes or outcomes also do not yet exist. The little empirical research that has 
been conducted in the military has significant internal and external validity problems, greatly limiting their power to inform prevention or intervention practices, which is the basic goal of resilience research.

\section{Lessons for the Bulgarian Military}

The concept of resilience is new and almost unknown in Bulgaria. It is even less known in the Bulgarian military. Although it is broadly implemented both as research projects and practical approaches in most NATO armies, there is neither research carried nor training programmes, based on the theory and practice of resilience in the Bulgarian military.

Resilience training should be intended to move from a deployment-cycle requirement to standard Army-wide training and assessment that takes place throughout a soldier's career. There should be an attempt to make resilience training more thorough. Resilience training should also be nested in Army operations and leadership, rather than under Army medical purview. And last, but not least, resilience training should be pushed towards evidence-based policymaking.

The Bulgarian military should focus its resilience-building efforts on the promotion of psychological resilience, at least in part because of its long tradition of viewing the qualities that contribute to operational resilience as sufficient to also ensure longterm psychological health and well-being in service members. In the traditional warrior ethos, qualities like courage and fortitude have been seen as the primary, if not sole, determinants of psychological resilience as well as resilience on the battlefield. The logical flip-side of this belief has been that those who lacked psychological resilience after returning from a theatre of war must also have been lacking in courage and fortitude. ${ }^{16}$ Such attitudes might lead to the conclusion that stress disorders such as post-traumatic stress disorder (PTSD) are not legitimate illnesses or injuries, even among those who provide healthcare in the military.

Regardless of attitudes and traditional beliefs, the goal of psychological resilience programmes must be to prevent long-term psychological distress or dysfunction and, instead, to encourage psychological health, strength, and well-being. These are the clear goals set for military psychological health programmes. In its report, the US Department of Defense Task Force on Mental Health established four overarching goals for military psychological health programmes: (1) build a culture of support for psychological health in the military; (2) ensure the availability to service members and their families of a full continuum of excellent care; (3) provide sufficient resources to achieve these ends; and (4) empower line military leaders to plan and coordinate integrated prevention, identification, and treatment efforts. ${ }^{18}$ 
The core competencies gained through resilience training should include (a) selfawareness - identifying one's thoughts, emotions, and behaviours, and patterns in each that are counterproductive; (b) self-regulation - the ability to regulate impulses, thinking, emotions, and behaviours to achieve goals, as well as the willingness and ability to express emotions; (c) optimism - noticing the goodness in self and others, identifying what is controllable, remaining wedded to reality, and challenging counterproductive beliefs; (d) mental agility - thinking flexibly and accurately, perspective taking, and willingness to try new strategies; (e) character strengths - identifying the top strengths in oneself and others, relying on one's strengths to overcome challenges and meet goals, and cultivating a strength approach in one's unit; and (f) connection - building strong relationships through positive and effective communication, empathy, willingness to ask for help, and willingness to offer help.

\section{References}

1. Frank Hoffman, Conflict in the 21st Century: The rise of Hybrid Wars (Arlington, VA: Potomac Institute for Policy Studies, 2007).

2. Jan Pospisil, "Resilienz: Die Neukonfiguration von Sicherheitspolitik im Zeitalter von Risiko," Austrian Journal of Political Science 1 (2013): 18-42.

3. Norman Garmezy, "Vulnerability Research and the Issue of Primary Prevention," American Journal of Orthopsychiatry 41 (1971): 101-116.

4. Michael Rutter, "Protective Factors in Children's Responses to Stress and Disadvantages," in Primary prevention of psychopathology, ed. M.W. Kent and J. E. Rolf (Hanover: University Press of New England, 1979), 49-74.

5. Alastair McAslan, "The Concept of Resilience. Understanding its Origins, Meaning and Utility," (Adelaide, Australia: Torrens Resilience Institute, 2010).

6. James Brassett, Stuart Croft, and Nick Vaughan-Williams, "Introduction: An Agenda for Resilience Research in Politics and International Relations," Politics 33, no. 4 (2013): 221 $-228$.

7. Jonathan Joseph, "Resilience as Embedded Neoliberalism: A Governmentality Approach," Resilience 1, no. 1 (2013): 38 - 52.

8. Myriam Dunn Cavelty and Tim Prior, "Resilience in Security Policy: Present and Future," CSS Analysis in Security Policy, no. 142 (October 2013):142.

9. Jānis Bērziṇš, "Russia's New Generation Warfare in Ukraine: Implications for Latvian Defense Policy," Policy Paper no. 02 (Riga: National Defence Academy of Latvia Centre for Security and Strategic Research, 2014).

10. Bastian Giegerich, "Hybrid Warfare and the Changing Character of Conflict," Connections: The Quarterly Journal 15, no. 2 (2016): 65 - 72.

11. Jan Joel Andersson, "Hybrid Operations: Lessons from the Past," ESS Brief 33 (2015), https://www.iss.europa.eu/content/hybrid-operations-lessons-past. 
12. Ian Anthony, Camille Grand, and Patricia Lewis, Towards a New European Security Strategy? Assessing the Impact of Changes in the Global Security Environment, (Luxembourg: Publications Office, 2015).

13. Franz Samelson, "World War I Intelligence Testing and the Development of Psychology," Journal of the History of Behavioral Sciences 13, no. 3 (July 1977): 274-282.

14. Brett T. Litz, Susan M. Orsillo, Matthew Friedman, Peter Ehlich, and Alfonso Batres, "Post-Traumatic Stress Disorder Associated with Peacekeeping Duty in Somalia for U.S. Military Personnel," American Journal of Psychiatry 154, no. 2 (February1997): 178-184.

15. Brett T. Litz, "Research on the Impact of Military Trauma: Current Status and Future Directions," Military Psychology 19, no. 3 (2007): 217-238.

16. William P. Nash, "Combat/Operational Stress Adaptations and Injuries," in Combat Stress Injuries: Theory, Research, and Management, ed. Charles R. Figley and William P. Nash (New York: Routledge, 2007).

17. Brett Litz, Lynda King, Daniel King, Susan Orsillo, and Matthew Friedman, "Warriors as Peacekeepers: Features of the Somalia Experience and PTSD," Journal of Consulting and Clinical Psychology 65, no. 6 (1997): 1001-1010.

18. Department of Defense Task Force on Mental Health, "An Achievable Vision: Report of the Department of Defense Task Force on Mental Health," (Falls Church, VA: Defense Health Board, 2007).

\section{About the author}

Lieutenant Colonel Krassen DASKALOV is a medical doctor working at the Centre for Mental Health and Prevention, Military Medical Academy; 3, "Sv. Georgi Sofijski” Blvd., Sofia 1606, Bulgaria. 